\title{
Characterising the policy influence of peer-based drug user organisations in the context of hepatitis $\mathrm{C}$ elimination
}

\author{
Graham Brown ${ }^{\mathrm{a}, \mathrm{f}, \mathrm{g}, *}$, Gari-Emma Perry ${ }^{\mathrm{b}}$, Jude Byrne ${ }^{\mathrm{c}}$, Sione Crawford ${ }^{\mathrm{d}}$, Charles Henderson ${ }^{\mathrm{e}}$, \\ Annie Madden ${ }^{\mathrm{f}}$, Roanna Lobo ${ }^{\mathrm{f}}$, Daniel Reeders ${ }^{\mathrm{h}}$ \\ ${ }^{a}$ Australian Research Centre in Sex, Health and Society, La Trobe University, Bundoora, 3086, Victoria, Australia \\ ${ }^{\mathrm{b}}$ Peer-based Harm Reduction WA, PO Box 8003, Perth WA 6849, Australia \\ ${ }^{\text {c } A u s t r a l i a n}$ Injecting \& Illicit Drug Users League, GPO Box 1555, Canberra ACT 2601, Australia \\ ${ }^{\mathrm{d}}$ Harm Reduction Victoria, PO Box 12720 A'Beckett Street, Melbourne, Australia \\ ${ }^{\mathrm{e}}$ New South Wales Users and AIDS Association, PO Box 350, Strawberry Hills, NSW 2012, Australia \\ ${ }^{\mathrm{f}}$ Centre for Social Research in Health, University of New South Wales, UNSW Sydney, NSW 2052, Australia \\ ${ }^{g}$ STI and BBV Applied Research and Evaluation Network, School of Public Health, Curtin University, GPO Box U1987, Perth WA 6845, Australia \\ ${ }^{\mathrm{h}}$ School of Regulation and Global Governance, Australian National University, Canberra ACT 2600, Australia
}

\section{A R T I C L E I N F O}

\section{Keywords:}

People who inject drugs

Peer organisation

Peer based program

Peer leadership

Policy and advocacy

Hepatitis C

Systems thinking

Advocacy

\begin{abstract}
A B S T R A C T
Background: Achieving hepatitis C (HCV) elimination goals will require major policy and health service reorientation to scale up testing and treatment among people who inject drugs (PWID). To achieve this, a close partnership with peer-based drug user organisations is required. However, peer organisations have historical and ongoing difficulties in articulating the validity of their service delivery and policy advice, leading to some policy and health services resisting partnership and advice from peer-based drug user organisations.

Methods: To develop a deeper understanding of the role of peer-based drug user organisations in the HCV response, we analysed data from the W3 Project which used systems thinking methods to draw together the insights of over 90 peer staff from 10 Australian community and peer organisations in HCV and HIV. The resulting system maps were analysed to identify system dynamics and functions that need to be fulfilled for peer organisations to be influential within their community and policy system.

Results: We identified the interactions at a system level which can enhance or constrain the quality and influence of policy advice from peer-based drug user organisations. We found the strength of Peer-based drug user organisations to support the scale up of HCV testing and treatment was their capacity to mediate between, and navigate within, the complex community and policy/health service systems. While peer-based drug user organisations endeavour to demonstrate their capacity and credibility in terms of engagement, alignment, adaptation and influence, policy and service organisations also need recognise their own system role to value and enable peer-based drug user organisations to achieve their potential.

Conclusion: If the HCV prevention and treatment system is to reach PWID living with HCV and achieve HCV elimination goals, then policy and health services need to invest in strengthening peer-based drug user organisations as well as recognise, value and act on quality policy advice from PWID peer leadership.
\end{abstract}

\section{Background}

Introduction

The global response to hepatitis C (HCV) is undergoing unprecedented if somewhat uneven, developments in prevention and treatment. The importance of increasing access to, and uptake of, direct acting antivirals (DAA) among people who inject drugs (PWID) to improve health outcomes and reduce prevalence has been shown to be a key part in reducing the ongoing transmission of HCV (Grebely et al., 2015; Martin et al., 2016; Scott et al., 2017). Modelling suggests that modest levels of HCV treatment may achieve elimination targets among

\footnotetext{
*Corresponding author at: Australian Research Centre in Sex, Health and Society, La Trobe University, Bundoora, 3086, Victoria, Australia.

E-mail addresses: graham.brown@latrobe.edu.au (G. Brown), accreditation@harmreductionwa.org (G.-E. Perry), judeb@aivl.org.au (J. Byrne), sionec@hrvic.org.au (S. Crawford), charlesh@nuaa.org.au (C. Henderson), annie.madden@unsw.edu.au (A. Madden), Roanna.Lobo@exchange.curtin.edu.au (R. Lobo), daniel.reeders@anu.edu.au (D. Reeders).
} 
PWID, particularly when combined with harm-reduction and networkbased strategies (Hellard et al., 2015; Pitcher, Borquez, Skaathun, \& Martin In press, online). However, current levels of testing and treatment will be insufficient to achieve elimination (Pitcher et al. In press, online). To achieve HCV elimination goals (Ward, 2016) will require equity of access for prevention, testing and treatment, which will require policy and health service changes, investment and scale up of services, and reductions in stigma and discrimination within health systems. The importance of peer-based programs to the effective rollout of new HCV treatments among PWID has been discussed in detail elsewhere (Batchelder et al., 2017; Bonnington \& Harris, 2017; Henderson et al., 2017; MacLellan et al., 2017). However, the role of peer organisations in supporting the reorientation or refinement of drug and health service policy, a key element of prevention, testing and treatment scale-up, has received less attention.

This paper will briefly describe peer-based PWID programs, the complexity of the system in which they operate, and their relationship to achieving HCV elimination goals. It will then describe the W3 project which drew on complex systems theory and methods to understand the role of peer organisations in the response to HCV and HIV. The paper will draw on this research to identify and discuss the implications for achieving high quality community insights and policy advice from peerbased drug user organisations, and for maximising the influence of this advice in policies and strategies to eliminate HCV.

\section{Peer-based drug user organisations}

Peer based programs with PWID have been part of the health promotion and health service landscape for decades, originating in Western Europe and North America in the late 1960s, and evolved, developed and expanded through the $80 \mathrm{~s}$ and $90 \mathrm{~s}$ in response to HIV and hepatitis C (Needle et al., 2005). The traditional service provider-client model of health care workers and top-down education approach of public health resulted in a push back and the formation of user-based (later referred to as "peer-based") interventions, and the "Nothing About Us, Without Us" philosophy (Jurgens, 2008). Navigating highly political contexts and circumstances has been a hallmark of these peer organisations (Madden \& Wodak, 2014), with the peer-based approach often undermined in the tensions between harm reduction based health promotion and the stigmatization and criminalization of drug use generally, and injection drug use in particular, across much of the world (Dechman, 2015; Ratliff et al., 2016). Policy reviews in Australia have found that a range of factors create and sustain barriers to HCV prevention, testing and treatment, and limit the reach of peer-based programs to PWID. These factors include negative societal attitudes towards injecting drug use and PWID, inconsistent application of evidence in policy making, concerns about public opinion, and the complex nature of legislative, policy and service delivery environments (Legal and Discrimination Working Party of MACBBVS, 2013).

Despite these challenges, PWID have demonstrated that they can self-organise as peer organisations, broadening the dissemination of knowledge, practices and equipment, as well as reflecting the reality of the lives of marginalised populations into policy and health service reforms (Dechman, 2015; Jurgens, 2008). The common descriptors of peer work have been categorised into direct harm reduction and health services; support, counselling, and referrals; research assistance; and advisory committee participation (Marshall et al., 2015). PWID peer workers have been found to assist in establishing more effective communication between clients and service providers and act as a 'bridge' in building or rebuilding trust and credibility and co-creating effective responses (AIVL, 2015).

Peer-based responses by PWID have been the subject of research for many years, resulting in a growing evidence base regarding their role in prevention of drug related harm, viral hepatitis, HIV and sexually transmittable infections and other health outcomes (for examples see Hay et al., 2017; Jain et al., 2014; Keats et al., 2015; McNeil et al.,
2014; Ti et al., 2015; Treloar et al., 2015), and their role as an integrated component of, or complement to, other health care initiatives (for a recent example see Bajis et al., 2017).

However, Marshall et al. (2015) note that describing the tasks of peer programs does not capture the strengths of peer-based programs nor the need for fundamentals such as the full participation of PWID. Often the level of participation of peers in health services is "functional", meaning peers are recruited to contribute to pre-defined objectives, with a range of political, health system and social structures acting as either barriers or enablers to stronger participation or influence (Bonnington \& Harris, 2017; Marshall et al., 2015). Recently, there has been an emergence of critical reflection on the ways social structures, policies, HCV and drug services, research priorities, and social identity all impact on how peer programs and services are conducted, viewed and experienced by PWID as well as the broader policy and health sector (Ashford et al., 2018; Batchelder et al., 2017; Bonnington \& Harris, 2017; MacLellan et al., 2017; Tookey et al., 2018).

Peer-based drug user organisations, which may conduct a range of peer programs, often have difficulties in articulating their role, demonstrating their quality and community (peer) connection, and showing their effectiveness (Bajis et al., 2017; Crawford \& Bath, 2013). In practice, most peer organisations are not resourced to undertake evaluation (Hayashi et al., 2010) or struggle with evaluating the complexity of the peer programs, the communities they work within, and the political contexts they need to navigate (Brown et al., 2015; Needle et al., 2005). The role of peer leadership and advocacy from peer organisations is often under recognised and the ways peer organisations contribute to the reorientation and refinement of broader policy or health service reform has been largely undocumented (Brown et al., 2015; Madden \& Wodak, 2014; Marshall et al., 2015; O'Gorman et al., 2014). These limitations can result in community insights and policy advice from peer-based drug user organisations being undervalued (Brown et al., 2015; Madden \& Wodak, 2014; Marshall et al., 2015; O'Gorman et al., 2014). These combined deficits can function as policy and health services resistance to partnership and advice from peerbased drug user organisations at a critical time whereby community insights will be essential to effective scaling up and targeting of HCV prevention, testing and treatment efforts.

\section{What works and why (W3) project}

The What Works and Why (W3) Project took on the challenge to answer questions such as:

what are the mechanisms by which peer organisations can demonstrate that their community insights and policy advice can be trusted and valued by the HCV sector?

; and how can the broader policy and health sector support peer organisations to fulfil their community and policy roles? To do this, the W3 Project (www.w3project.org.au) recognised that a deeper understanding of the role of peer-based drug user organisations as part of a complex and adapting response to HCV was required. Using systems thinking and participatory methods the project developed a framework to articulate and evaluate the contribution of peer organisations in their PWID communities as well as the broader 'enabling environment' in relation to HCV and PWID communities.

Brown et al. (2018) provides a detailed overview of the W3 Project methods and a description of the findings for the evaluation of peer programs working with communities of gay men, sex workers, people living with HIV and PWID. This paper draws on the specificity of the PWID system map developed in the study (not described in Brown et al. 2018) to identify the implications for the role of peer organisations in influencing policy, particularly in HCV health services and treatment access. 
Table 1

The W3 Collaboration.

W3 Project: Understanding what works and why in peer-based and peer-led programs in HIV and hepatitis $C$

- Australian Federation of AIDS Organisations (the national peak body for the community-based response to HIV),

- Australian Injecting and Illicit Drug Users League (the national peak body for people who use drugs peer organisations),

- Harm Reduction Victoria (people who use drugs peer organisation),

- Western Australian Substance Users Association (people who use drugs peer organisation),

- Victorian AIDS Council (community and peer-based organisation with services for gay and bisexual men, people who inject drugs, and people with HIV),

- Scarlet Alliance - Australian Sex Workers Association (national peer-based sex worker organisation),

- National Association of People Living with HIV/AIDS (national people with HIV peer organisation),

- Living Positive Victoria (people with HIV peer organisation),

- Positive Life New South Wales (people with HIV peer organisation),

- Queensland Positive People (people with HIV peer organisation),

In Australia "community based" and "peer-based" and are the dominant organisational descriptors. These organisations were established by the communities most affected by HIV from the mid-1980s, and their governance is based within their communities. The majority of their limited funding comes from national and state governments with varying contracting conditions and caveats. Community based organisations at a policy level are considered part of the "HIV partnership" alongside clinical services, research, and government. As with most countries, these relationships have waxed and waned over the past three decades. For a summary of the history of the community response in Australia see (Brown, O’Donnell, Crooks, \& Lake, 2014)

\section{Methods}

The W3 Project conceptualised peer-based programs, including the communities and policy environments they engage with, as elements in a complex system (Holland, 2006; Meadows \& Wright, 2008; Midgley, 2003; Ostrom et al., 2002). What systems thinking brought to this research was an understanding that for peer-based programs, the way communities of PWID enhance, adapt, resist or ignore peer-based programs are an inherent part of the program and something to be leveraged and built on, not resisted or treated as a confounder (Brown et al., 2015). This system thinking directed our attention to the synergies and leverage points that can occur in communities and in policy environments as the system adapts and evolves (Luke \& Stamatakis, 2012; Mabry \& Kaplan, 2013; Midgley, 2003). The W3 Project was conducted over three phases, and is described in detail elsewhere (Brown et al., 2018). The phases are summarised below.

\section{Phase 1-participatory workshops to develop system maps}

Over a two-year period, we conducted a series of 18 workshops ranging from one to two days each with the ten organisations (see Table 1) to elicit and diagram mental models (system maps) of how peer-based programs operate. The organisations invited key peer staff and volunteers to participate resulting in over 90 peer staff and volunteers being involved across the workshops. All programs included drug use within their programs and peer context. Three of the organisations were specifically peer-based drug user organisations (two state/ jurisdictional and one a national peak organisation which conducted programs and policy advice at a national level on behalf of state/jurisdictional organisations) and included 23 peer staff who participated in the workshops.

In the workshops we drew on complex systems theory (Holland, 2006; Meadows \& Wright, 2008; Ostrom et al., 2002) and systems thinking methods (specifically soft systems methods as described by Checkland (2000) and Williams and Hummelbrunner (2010)) to elicit and diagram mental models of how peer-based programs operate. We utilised causal loop diagram methods (Meadows \& Wright, 2008; Williams \& Hummelbrunner, 2010) to help identify the regular (i.e. cyclical) relationships or 'causal loops' among the higher-level themes. Through these highly participatory qualitative methods, we drew on the experience and perspectives of peer practitioners working in outreach, community development, workshop facilitation, policy reform and leadership, management and governance. During the workshops we developed and revised a series of system maps describing what peerstaff theorised happens during these peer-based programs, and the

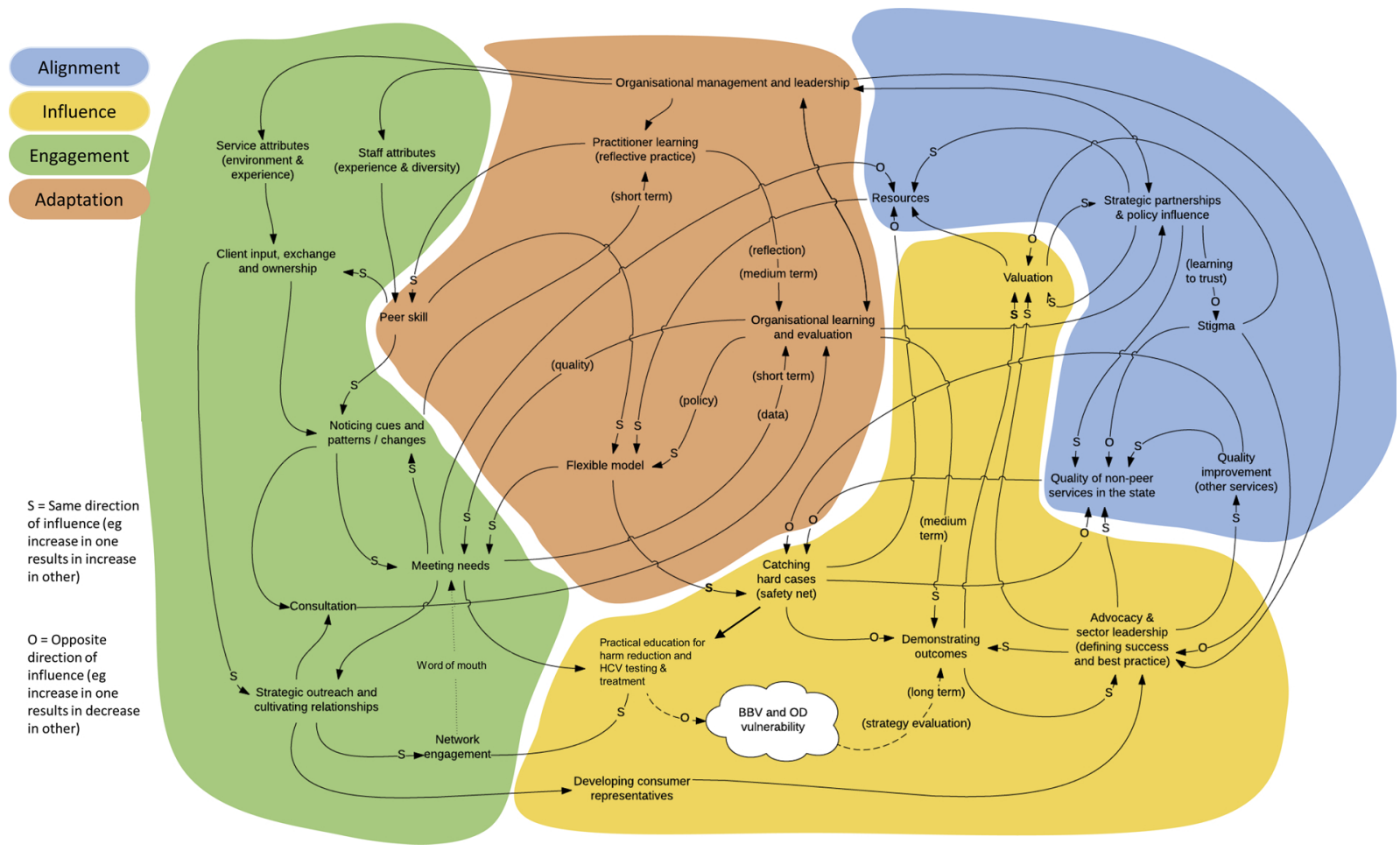

Fig. 1. PWID Peer Service and Policy Participation System Map. 
program's relationships with all the components of the community and policy system within which they were situated. The dynamics of the relationships within the system maps were identified, discussed, debated and refined within the workshops.

In reviewing the system maps, system dynamics operating within these complex systems were identified and compared on an iterative basis with the emerging dynamics from the other systems maps being developed (ie peer-based programs with gay men, sex workers, and people living with HIV). These comparisons were then presented to the peer-based drug user organisations for discussion and reflection. The final system map for PWID peer-based programs is presented in Fig. 1. Detailed descriptions of this system map and other system maps developed by the study are available online (Brown \& Reeders, 2016).

Phase 2-analysis of system maps to identify common themes and functions

Drawing on the realist evaluation work of Pawson and Tilley (1997) we analysed the full set of complex system maps to identify the key underlying functions. The realist approach criticises the experimental paradigm of evaluation that looks for a direct cause and effect relationship independent of the program's social context. Instead the realist approach theorises how programs achieve desired outcomes by understanding the mechanisms (or functions) and how they operate within and interact with their social context. Envisioning the peer program as an organism and its community and policy contexts as its surrounding ecology, we asked what functions do peer programs and organisations need to be equipped with to be influential, sustainable and adapt to changes in their environment. We analysed the maps for functions that occurred across all the system maps. Through this we identified four key functions which a peer based program must be able to fulfil in order to be effective and sustainable as it mediates between continually changing community and policy environments. These functions formed the basis of the draft W3 Framework.

Phase 3-review and refinements by organizations locally and validated nationally

The draft W3 Framework, as well as the PWID system map, was subjected to additional review at a national meeting of all peer-based drug user organisations in Australia (involving an additional 11 participants from three state/jurisdictional peer-based drug user organisations in Australia who had not been directly involved in the study). Peer staff reviewed descriptions of the system dynamics within the system map (Fig. 1) and reviewed the W3 Framework (Fig. 2 and Table 2). Input was discussed by the group and the findings were endorsed as consistent with the experience of all the participating peer-based drug user organisations. Similar validation processes were undertaken with peer organisations working with gay men, people living with HIV, and sex workers.

The study was provided ethical approval by the La Trobe University Human Research Ethics Committee (Approval No: FHEC14/155).

\section{Results}

The W3 Project found that peer organisations operate within a complex and constantly changing system, comprising of community and policy system elements. The PWID Peer Service Provision and Policy Participation System Map (hereafter referred to as the System Map, Fig. 1), illustrates the detail of the relationships between the peerbased organisations and these system elements. The System Map (Fig. 1), is one of the system maps described in the methods above, which led to the development of the W3 Framework (Brown \& Reeders, 2016). The W3 Framework (Fig. 2) takes a higher-level view and simplifies this complexity into functions, and illustrates the relationships between the functions. In describing the results below, we briefly describe the functions within the W3 Framework (Fig. 2). We then draw on these high-level functions to explain selected system dynamics within the System Map (Fig. 1) which relate to the role and capacity of peer-based drug user organisations to influence policy and health service responses to eliminate hepatitis $\mathrm{C}$.

\section{System level functions of a peer organisation}

The W3 Framework (Fig. 2) recognises that peer-based drug user organisations operate within and between two interrelated and constantly changing complex systems - the community system and the policy system - illustrated by the cloud images on the left and right of Fig. 2. The community system is comprised of the diverse and evolving networks and cultures of PWID within which the peer organisations participate. The policy system includes the diverse network of health services, community organisations, policy actors, law enforcement, researchers, politicians and other sectoral stakeholders. Both the community and policy systems are constantly changing. The W3 framework sets out four functions (in orange) that peer-based programs need to sustain to be effective and influential in these complex and dynamic systems. These functions are Engagement, Alignment, Adaptation and Influence (see Table 2 for definitions). The focus on the system elements and how they interact with each other is what differentiates the W3 Framework from other understandings of peer-based programs (Hildebrand et al., 2012; Marshall et al., 2015; Webel et al., 2010) and enhances our understanding of the participation of PWID peers in research and policy (Greer et al., 2018; Jozaghi et al., 2018; Keats et al., 2015; Treloar et al., 2015).

Overview of the PWID Peer service provision and policy participation system map

The detailed system map in Fig. 1 includes a large number of elements, illustrating how peer-based drug user organisation service delivery, practical education, and advocacy is interconnected and nested within the alcohol and other drug service sectors, policing and judicial systems, and the blood borne virus prevention and treatment sector. To show the way system dynamics within the system map (Fig. 1) flow through the W3 functions of engagement, alignment, adaptation, and influence, we have shaded in colour the domains of the system map related to each function. We use the W3 functions to summarise selected system dynamics and identify the implications for the role of peer organisations in influencing policy, particularly policy related to the provision of HCV health services and treatment access. Where the discussion refers to identified items within the system map in Fig. 1, the name of the item has been italicised. The system map in Fig. 1 is described in more detail elsewhere (Brown \& Reeders, 2016) and in the supplementary material to this paper.

\section{Engagement within the PWID community system}

A key component of engagement for peer-based drug user organisations is the interaction and exchange between PWID community members and peer staff. The capacity for peer organisations to listen and reflect on what community members tell peer workers about their needs and recent developments within their networks means community members don't come to the peer organisation empty handed: they have knowledge to share in the service exchange. For example, in Fig. 1, in the engagement (green) domain, we found the experience and diversity of peer staff (staff attributes) is enhanced through their ability to combine their own personal experience with their broader understanding of the community through service delivery and apply this within a program (peer skill). These attributes are complemented by the welcoming environment and experience of peer program (service attributes). Through this, community members not only access services, but also provide feedback and share their knowledge of community issues (client input, exchange and ownership). This knowledge might include 


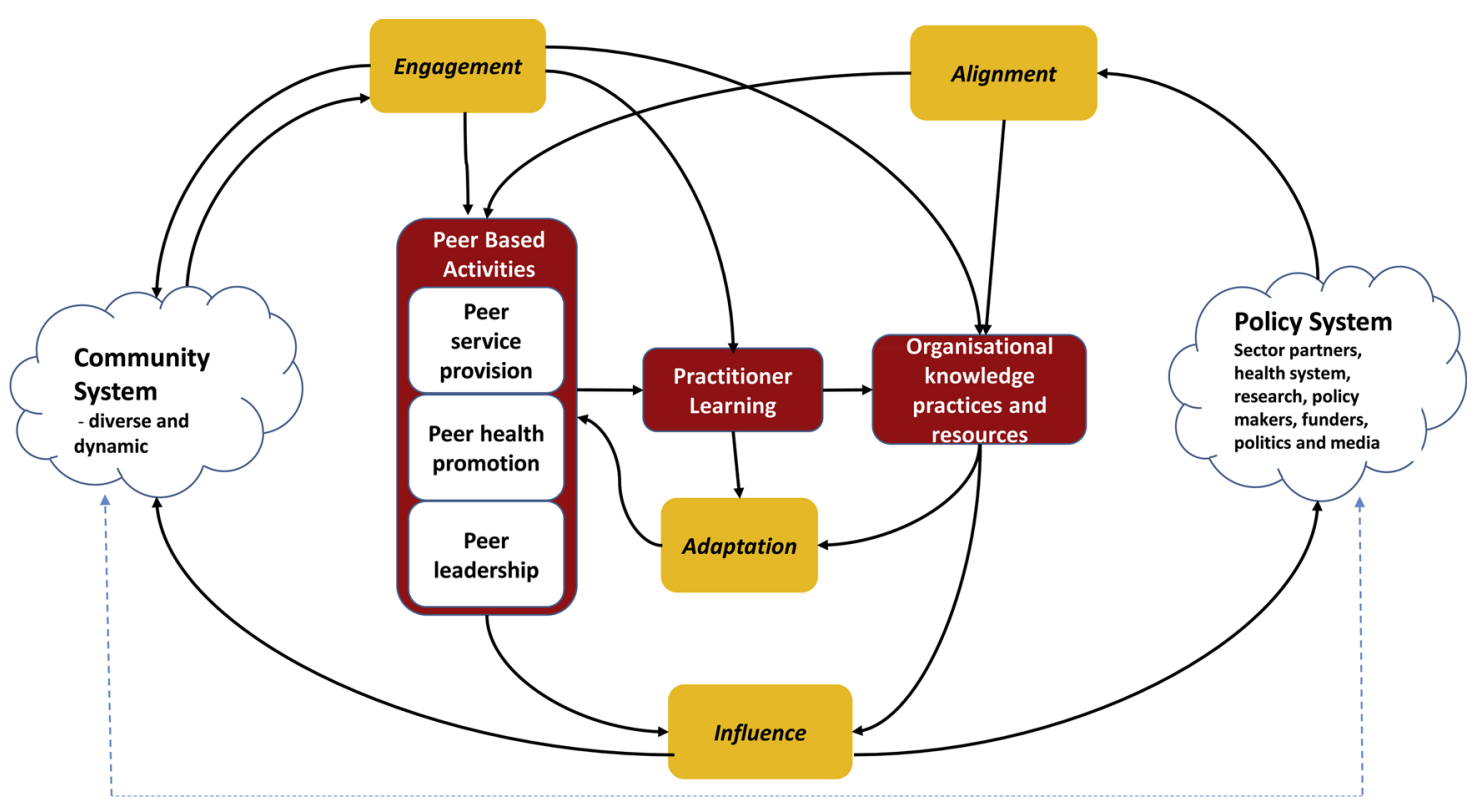

Fig. 2. W3 Framework.

drug quality, police operations, changing PWID cultures and practices, experiences of health services and treatment, and other enablers and barriers. The interaction and sharing with community members enables peer staff to notice cues, patterns and changes, and use this to meet needs, as well as target strategic outreach and cultivate relationships within diverse PWID networks. Refining peer programs increases the peer organisation's network engagement (or 'reach') and generate word of mouth credibility in the community regarding the peer service. Community members accessing the service share insights as they believe that the peer-service will use that information for the betterment of the PWID community. These peer interactions provide the opportunity for peer staff to constantly refine their shared collective understanding of the experiences of their community.

\section{Learning and adaptation of peer skill and leadership in tandem with a} changing and diversifying system

Peer organisations need to draw what they can from their communities (through engagement) but then 'test the waters' as they adapt with their communities. This adaptation is across the range of activities of peer service delivery (such as peer-based needle and syringe program), peer health promotion (such as peer developed harm reduction information and community development), or peer leadership (such as peers taking leadership roles in their community, their sector, or participating in policy reform). For peer-based drug user organisations the concept of 'peer skill' - the ability to combine personal experience and ongoing community and network connections, feed these insights into a peer organisation's constantly updated collective understanding of the community, and then apply this within their peer work - was key to peer-based programs being able to work effectively within a diverse community and complex policy system. As illustrated in Fig. 1, in the Adaptation (brown) domain, peer worker learning (practitioner learning) is influenced by peer workers noticing cues and patterns within their community (from the Engagement domain) and the support and leadership from the organisation (organisational management and leadership). The combining of practitioner learning and staff attributes is a key influence on peer skill. However, turning this peer worker knowledge into a broader collective understanding in the organisation requires

Table 2

Elements and Functions of the W3 Framework.

\begin{tabular}{|c|c|c|}
\hline \multicolumn{2}{|l|}{ Element } & Definition \\
\hline \multicolumn{2}{|l|}{ Community system } & The social networks and cultures the program engages with, and the processes of interaction and change that are taking place within them. \\
\hline \multicolumn{2}{|l|}{ Policy system } & The policy system includes funders, policy-makers, media, health services, research, and other organisations in the sector. \\
\hline \multicolumn{2}{|l|}{ Peer-based activities } & $\begin{array}{l}\text { Different kinds of peer-based and peer led approaches that depend on peer skill - the ability to combine personal experience and real-time } \\
\text { collective understanding to work effectively within a diverse community }\end{array}$ \\
\hline \multicolumn{2}{|l|}{ Practitioner learning } & Peer workers pick up insights from clients and contacts, and develop, test and refine mental models of their environment. \\
\hline \multicolumn{2}{|c|}{ Organisational knowledge practices } & $\begin{array}{l}\text { Program management encourages the discussion and capture of insights from practitioner learning as an asset for the organisation and for } \\
\text { sharing with stakeholders in the policy system. }\end{array}$ \\
\hline \multicolumn{2}{|l|}{ Arrows } & Flows of knowledge or causal influence that constitute the program as a system. \\
\hline System Level Functions & \multicolumn{2}{|c|}{ Explanation } \\
\hline Engagement & \multicolumn{2}{|r|}{$\begin{array}{l}\text { How the program participates within the PWID communities and networks and maintains up to date mental models of the diversity and dynamism of } \\
\text { needs, experiences and identities in its target communities. }\end{array}$} \\
\hline Alignment & \multicolumn{2}{|r|}{$\begin{array}{l}\text { How the program works within and picks up signals about what's happening in its policy and health sector environment and uses this to better } \\
\text { understand emerging policy issues and what may need to change to achieve better outcomes for the community. These changes may be either in the } \\
\text { policy, health or justice systems or in the peer programs and advocacy conducted by peer organisations. }\end{array}$} \\
\hline Adaptation & \multicolumn{2}{|r|}{$\begin{array}{l}\text { How the peer organisation changes and refines its understanding and approach based on insights from engagement and alignment. The foundation of } \\
\text { the adaptation is peer skill - the ability to combine personal lived experience within injecting drug use with a broader collective understanding of the } \\
\text { PWID community and apply this within peer services, peer health promotion or peer leadership (such as policy advice). }\end{array}$} \\
\hline Influence & \multicolumn{2}{|r|}{$\begin{array}{l}\text { How the program uses existing social and political processes to influence and achieve improved outcomes in both the community and the policy/sector } \\
\text { systems }\end{array}$} \\
\hline
\end{tabular}


peer staff and the organisation to share and value their understanding of the PWID community diverse needs, identities, and experiences. For effective community insights to feed into policy advice, the insights from practitioner learning need to be shared across the network of current and emerging PWID peer leaders (organisational learning and evaluation) to maintain an up-to-date understanding of the current experiences of the PWID community. This is essential for the peer organisation to keep adapting (flexible model) as well as interact with strategic partnerships and policy influence in the alignment (blue) domain.

\section{Influence of peer-based drug user organisations within community systems}

A key element of peer-based drug user organisations maintaining their influence in their communities, as illustrated in Fig. 1 in the influence (yellow) domain, is the relevance of their peer-based practical education for harm reduction and HCV testing and treatment. The relevance of the education is underpinned by capacity and resources to adapt and remain flexible (flexible model in brown adaptation domain, meeting needs in the green engagement domain), and the quality and depth of their engagement within PWID networks (network engagement). The high flexibility of the programs means that peer organisation have the opportunity to adapt with their community and meet the needs of PWID who may have complex barriers to harm reduction or treatment uptake and distrust health services (catching hard cases). However, the more complex cases peer organisations respond to, the less pressure there can be on some other mainstream services and policies to be flexible or non-stigmatising for such complex cases (quality of non-peer services in the state).

\section{Influence of peer-based drug user organisations within policy systems}

The W3 Project found that the influence of peer-based drug user organisations in the policy system was related to a number of factors: the visibility and demonstrability of engagement and authenticity within their community; the quality, timeliness and usefulness of previous policy participation; and the visibility in the sector of partner organisations valuing the policy participation of the peer-based drug user organisations. For example - in the influence (yellow) domain in the system map (Fig. 1), valuation (the value the sector places in the peer led model and its advice) was influenced by a number of system elements.

- Demonstrating outcomes of the work of the peer organisations - which was dependent on practitioner learning and peer skill being synthesised in organisational learning and evaluation (in the brown adaptation domain).

- Advocacy and sector leadership - which was dependent on the peer organisation undertaking strategic outreach and cultivating relationships (in the green engagement domain) to enhance their capacity to develop consumer representatives from diverse networks and experiences. An important part of the peer organisation was to identify, train and support PWID to participate as consumer representatives in focus groups, consultation processes, and committees formed around change processes and policy review. Supporting effective consumer representation was an important way in which peer organisations could maintain influence in policy and practice within the health and justice systems.

- The level of stigma and discrimination regarding PWID within the service and policy environment (in the blue alignment domain) played a key balancing or constraining role in the system. For example, the exclusion or dismissal of advice from people with current injecting experience, or legal sanctions marginalising such advice. Unchecked, this would undermine the valuation of any advice from peer-based drug user organisations by the sector, and so reducing the impact of the advocacy and sector leadership.

- Strategic partnerships and policy influence (in the blue alignment domain)- which had a reciprocal relationship with valuation, in that the stronger and more visible the peer organisation's strategic partnerships, the more the sector valued the peer organisation. The more the peer organisation was valued, the stronger the strategic partnerships and policy influence, and the more the sector organisations trusted the peer organisations (learning to trust) and so counter stigma within some policy and health service organisations. Learning to trust draws on the work of Sendziuk (2003) which describes the experience in Australia of policy makers and health services coming to trust and value the organised effort of affected communities in the response to HIV (and HCV), and consistent with the experience elsewhere (Jozaghi et al., 2018).

Alignment between peer organisations and leadership and the health and services policy system

It is through alignment that peer-based drug user organisations pick up insights into changes in the policy system (government policy, health services, epidemiological and social research), as well as gauge their own influence within that policy system. As illustrated in Fig. 1, for the other system functions to be effective, the sector needs to be willing to share real-time insights and work towards an alignment (or reduce the misalignment) between the policy, law enforcement, health service and peer organisation elements of the system (sector partnerships and policy influence).

\section{Discussion}

The strength of a peer organisation is the extent to which it is embedded in and participates in the social systems and community tensions it is endeavouring to influence, and so able to identify and respond to the emerging issues and experiences of the PWID community. Systems thinking approaches (Hawe et al., 2009; Peters, 2014) remind us that not only are things constantly changing within drug use communities and drug and treatment policy systems, but these changes are often emergent and not always predictable.

To describe how PWID organisations navigate emerging aspects of the system, we found the concept of 'peer skill' was particularly useful. The definition of who is and is not a peer within harm reduction and peer-based drug user organisations varies much across the literature and within programs. In most cases the definition of peer is people who have lived experience of substance use and who use that knowledge to inform their work (Greer et al., 2019). However, we found that drawing only on one's own lived experience - whether current or past - was not enough to be an effective peer worker in such a dynamic community. Rather than debating who is or is not a peer across such a diverse community, taking a systems perspective allowed us to focus on the role that peer workers needed to play within a system. This role included the ability to gain peer insights from both personal experience and ongoing community and network connections, the opportunity to contribute this to the peer organisation's collective understanding of the community, and the capacity to draw on this collective understanding in their peer service delivery or advocacy work. These peer insights might include how knowledge of new HCV treatment options are diffusing (or not) within different networks of PWID; or the effectiveness of service reforms to reduce structural barriers; or tracking how the scale up of HCV treatment may be disrupting the manifestation of stigma within and towards the drug-using community (such as reducing the fear of transmission but unintentionally positioning those not accessing treatment as recalcitrant). A peer organisation's commitment and capacity to act on the peer insights they receive from engagement and then adapt, advocate and even pre-empt issues with their communities is what sustains their community's sense of trust, credibility and ownership in the peer organisation.

While peer-based drug user organisation can be the bridge between marginalised communities and policy and health services, they tread a 
fine line. For example, if a health service de-prioritises access to HCV treatment for people who are currently injecting, this will impact on the range of credible referrals a peer organisation can provide. If peer organisations refer their community to stigmatising health services this not only undoes the work of the peer organisation to support that community member to access services, but also undermines the credibility of the peer organisation. If peer organisations are viewed by members of their community as being an arm of a distrusted health or justice system, this can damage the peer organisations credibility in their community. Therefore, how a peer worker reflects the community needs and how they themselves are positioned within that community through the values and knowledge they exhibit, becomes the crucial guiding factor for credibility at the overall organisational level.

A peer-based drug user organisation that is restricted or constrained from engaging and adapting, be it due to lack of resources, flexibility or legal impediments, risks disconnecting from its community and so undermines its ability to maintain peer skill and be effective in community and policy systems. Whereas an enabling policy environmental that allows high adaptability enhances the relationship between the peerbased drug user organisation and their community, and so too the accuracy of the policy advice they can provide. Taking a systems perspective illustrates that delivering trusted and credible peer services and undertaking peer advocacy for policy or structural reform are intrinsically linked.

While effective advocacy required peer insights to be drawn together by peer organisations in a way that is useful for the sector, the W3 project found this is not enough to have influence. Consistent with the work of Marshall et al. (2015) and Dechman (2015) we found that not only are stigma and legal impediments regarding injecting drug use a reason peer programs in HCV prevention and treatment are needed, it is also a reason that genuine real time peer insights are difficult to gain, and a barrier to such insights being valued and acted on.

Similar to the work of Greer et al. (2019), we found that some peer participation in policy, service and research advice can be characterised by ad-hoc appointments and tokenism. We found that such peer knowledge and experience was often dismissed within some policy systems due to a range of individual, institutionalised and structural impediments to the involvement of PWID. We also found that effective advocacy outcomes depended on a congruence of opportunities, insights, policy and politics, which was consistent with policy literature concerning policy windows and multiple streams of influence (Howlett, McConnell, \& Perl, 2016; Kingdon, 2003).

However, in contrast to other studies, the W3 Project also identified system level factors which countered or minimised the impact of these challenges. The W3 Project found that to act on advice from peer-based drug user organisations, policy and service organisations need to be confident that the peer organisation could demonstrate breadth and depth of engagement with the PWID community and also be confident the resulting advice would be persuasive or valued in their organisation or the sector more broadly. The W3 Project found that peer-based drug user organisations who could: draw on and demonstrate sustained engagement with their community; use peer skill to interpret and present peer insights from this engagement within their advocacy; and build non-peer allies in the system to publicly value and endorse this advice, would be able to build a reputation that policy-makers and sector partners could come to trust and rely on for their input. Achieving this by themselves while navigating the complexity of the policy system can be an extremely high bar for often underfunded stigmatised organisations already navigating marginalised and illicit drug use cultures. Building on the work of Osborn and Small (2006), Jozaghi et al. (2018) and Greer et al. (2019), we found that central to achieving an enabling alignment between peer-based drug user organisations and the broader policy system was a commitment by the policy system to a peer-based response to HCV and a public valuing of PWID peer leadership and advocacy within that response.

\section{Conclusion}

It is well recognised in the literature that increasing access to and uptake of HCV treatment among PWID will be important to reducing prevalence and incidence of HCV (Grebely et al., 2015; Martin et al., 2016; Scott et al., 2017). It is also well recognised that the scale up of HCV treatment among PWID is a complex social, political and health policy challenge (Batchelder et al., 2017; Bonnington \& Harris, 2017; MacLellan et al., 2017). However, the opportunities of peer organisations to enhance this treatment scale up, in relation to elimination goals, and the role of the whole HCV response in supporting peer organisations to reach their potential, is less developed.

This paper has drawn on in-depth findings from the W3 Project work with peer-based drug user organisations. We found the strength of peer-based drug user organisations to support the scale up of HCV testing and treatment is their capacity to mediate between, and navigate within, the complex community and policy/health service systems. For peer-based drug user organisations to achieve this role, the organisation needs to be engaged and embedded in PWID communities and sustain rapport and trust as they adapt in tandem; and it needs to simultaneously provide peer leadership and policy participation that is accurate and grounded within the current experience of its community.

However, in exploring the system dynamics of the peer-based drug user organisations, we found that effective policy influence only partly depends on the quality of advocacy argument; it also relies on demonstrations of trust and alignment from non-peer organisations in the sector and policy networks. Influence in the policy system was as much about the policy system valuing the participation of peer leadership as it was about the quality or timeliness of the policy participation, and that these two elements could either reinforce or undermine each other.

peer-based drug user organisations generally have limited resources and draw on the resilience and expertise of communities already experiencing multiple stigma, legal, health management and health services barriers. peer-based drug user organisations are constantly managing accountability, credibility and institutionalised stigma within both their community and policy systems. There can often be misalignment of the policy, legal and sector systems which can undermine these system dynamics and so hamper investments in peer-based programs. While peer-based drug user organisations endeavour to demonstrate their credibility in terms of engagement, alignment, adaptation and influence, policy and service organisations also need recognise their own system role to value and enable peer-based drug user organisations to achieve their potential. If the HCV prevention and treatment system is to reach PWID living with HCV and achieve HCV elimination goals, then policy and health services need to invest in strengthening peer-based drug user organisations as well as identify, value and act on quality policy advice from PWID peer leadership.

\section{Disclosure of interest}

Graham Brown has received funding from the Australian Government Department of Health, ViiV Healthcare International, and the Australian Federation of AIDS Organisations. Other authors have received funding from Australian Government Department of Health and jurisdictional (state) Departments of Health. No pharmaceutical grants were received in the development of this study.

Gari-Emma Perry, Jude Byrne, Sione Crawford, and Charles Henderson currently work in peer organisations.

\section{Funding}

This study was funded by the Australian Government Department of Health. 


\section{CRediT authorship contribution statement}

Graham Brown: Conceptualization, Data curation, Formal analysis, Funding acquisition, Investigation, Methodology, Project administration, Visualization, Writing - original draft, Writing - review \& editing. Gari-Emma Perry: Conceptualization, Formal analysis, Visualization, Validation, Writing - review \& editing. Jude Byrne: Conceptualization, Formal analysis, Visualization, Validation, Writing - review \& editing. Sione Crawford: Validation, Writing - review \& editing. Charles Henderson: Validation, Writing - review \& editing. Annie Madden: Conceptualization, Formal analysis, Visualization, Validation, Writing review \& editing. Roanna Lobo: Formal analysis, Visualization, Writing - review \& editing. Daniel Reeders: Conceptualization, Data curation, Formal analysis, Investigation, Methodology, Visualization, Writing - review \& editing.

\section{Appendix A. Supplementary data}

Supplementary material related to this article can be found, in the online version, at doi:https://doi.org/10.1016/j.drugpo.2019.05.025.

\section{References}

AIVL (2015). Submission to House of Representatives Standing Committee on health inquiry into hepatitis C in Australia. Canberra: Australian Injecting and Illicit Drug Users League.

Ashford, R. D., Curtis, B., \& Brown, A. M. (2018). Peer-delivered harm reduction and recovery support services: Initial evaluation from a hybrid recovery community dropin center and syringe exchange program (Ashford2018) Harm Reduction Journal, 15(1), 52. https://doi.org/10.1186/s12954-018-0258-2.

Bajis, S., Dore, G. J., Hajarizadeh, B., Cunningham, E. B., Maher, L., \& Grebely, J. (2017). Interventions to enhance testing, linkage to care and treatment uptake for hepatitis $\mathrm{C}$ virus infection among people who inject drugs: A systematic review. International Journal of Drug Policy, 47, 34-46. https://doi.org/10.1016/j.drugpo.2017.07.002.

Batchelder, A. W., Cockerham-Colas, L., Peyser, D., Reynoso, S. P., Soloway, I., \& Litwin, A. H. (2017). Perceived benefits of the hepatitis $C$ peer educators: A qualitative investigation. Batchelder2017 Harm Reduction Journal, 14(1), 67. https://doi.org/10. 1186/s12954-017-0192-8.

Bonnington, O., \& Harris, M. (2017). Tensions in relation: How peer support is experienced and received in a hepatitis C treatment intervention. International Journal of Drug Policy, 47, 221-229. https://doi.org/10.1016/j.drugpo.2017.05.031.

Brown, G., O'Donnell, D., Crooks, L., \& Lake, R. (2014). Mobilisation, politics, investment and constant adaptation: Lessons from the Australian health-promotion response to HIV. Health Promotion Journal of Australia, 25, 35-41.

Brown, G., \& Reeders, D. (2016). What works and why-Detailed system map reportsMelbourne. Retrieved fromhttps://whatworkswhyproject.wordpress.com/ blog/publications/.

Brown, G., Reeders, D., Cogle, A., Madden, A., Kim, J., \& O'Donnell, D. (2018). A systems thinking approach to understanding and demonstrating the role of peer-led programs and leadership in the response to HIV and hepatitis C: Findings from the W3 project. Frontiers in Public Health, 6(231), https://doi.org/10.3389/fpubh.2018.00231.

Brown, G., Reeders, D., Dowsett, G. W., Ellard, J., Carman, M., Hendry, N., \& Wallace, J. (2015). Investigating combination HIV prevention: Isolated interventions or complex system. Journal of the International AIDS Society, 18(1), Retrieved from http://www. jiasociety.org/index.php/jias/article/view/20499.

Checkland, P. (2000). Soft systems methodology: A thirty year retrospective. Systems Research and Behavioral Science, 17(S1), S11-S58.

Crawford, S., \& Bath, N. (2013). Peer support models for people with a history of injecting drug use undertaking assessment and treatment for hepatitis $\mathrm{C}$ virus infection. Clinical Infectious Diseases, 57(Suppl_2), S75-S79.

Dechman, M. K. (2015). Peer helpers' struggles to care for "others" who inject drugs. International Journal of Drug Policy, 26(5), 492-500. https://doi.org/10.1016/j. drugpo.2014.12.010.

Grebely, J., Robaeys, G., Bruggmann, P., Aghemo, A., Backmund, M., Bruneau, J., \& Dore, G. J. (2015). Recommendations for the management of hepatitis C virus infection among people who inject drugs. International Journal of Drug Policy, 26(10), 1028-1038. https://doi.org/10.1016/j.drugpo.2015.07.005.

Greer, A. M., Amlani, A., Burmeister, C., Scott, A., Newman, C., Lampkin, H., \& Buxton, J. A. (2019). Peer engagement barriers and enablers: Insights from people who use drugs in British Columbia, Canada. Canadian Journal of Public Health, 1-9.

Greer, A. M., Amlani, A., Pauly, B., Burmeister, C., \& Buxton, J. A. (2018). Participant, peer and PEEP: Considerations and strategies for involving people who have used illicit substances as assistants and advisors in research. BMC Public Health, 18(1), 834. Retrieved from https://www.ncbi.nlm.nih.gov/pmc/articles/PMC6034321/pdf/ 12889_2018_Article_5765.pdf.

Hawe, P., Shiell, A., \& Riley, T. (2009). Theorising interventions as events in systems. American Journal of Community Psychology, 43(3), 267-276.

Hay, B., Henderson, C., Maltby, J., \& Canales, J. J. (2017). Influence of peer-based needle exchange programs on mental health status in people who inject drugs: A nationwide
New Zealand study. Frontiers in Psychiatry, 7, 211.

Hayashi, K., Wood, E., Wiebe, L., Qi, J., \& Kerr, T. (2010). An external evaluation of a peer-run outreach-based syringe exchange in Vancouver, Canada. International Journal of Drug Policy, 21(5), 418-421. https://doi.org/10.1016/j.drugpo.2010.03. 002 .

Hellard, M., McBryde, E., Sacks Davis, R., Rolls, D. A., Higgs, P., Aitken, C., \& Robins, G. (2015). Hepatitis C transmission and treatment as prevention - The role of the injecting network. International Journal of Drug Policy, 26(10), 958-962. https://doi. org/10.1016/j.drugpo.2015.05.006.

Henderson, C., Madden, A., \& Kelsall, J. (2017). Beyond the willing and the waiting: The role of peer-based approaches in hepatitis $\mathrm{C}$ diagnosis and treatment. International Journal of Drug Policy, 50, 111-115. https://doi.org/10.1016/j.drugpo.2017.08.004.

Hildebrand, J., Lobo, R., Hallett, J., Brown, G., \& Maycock, B. (2012). My-peer toolkit [1.0]: Developing an online resource for planning and evaluating peer-based youth programs. Youth Studies Australia, 31(2), 53.

Holland, J. H. (2006). Studying complex adaptive systems. Journal of Systems Science and Complexity, 19(1), 1-8.

Jain, B., Krishnan, S., Ramesh, S., Sabarwal, S., Garg, V., \& Dhingra, N. (2014). Effect of peer-led outreach activities on injecting risk behavior among male drug users in Haryana, India. Harm Reduction Journal, 11, 3. https://doi.org/10.1186/1477-751711-3.

Jozaghi, E., Greer, A. M., Lampkin, H., \& Buxton, J. A. (2018). Activism and scientific research: 20 years of community action by the Vancouver area network of drug users. Substance Abuse Treatment, Prevention, and Policy, 13(1), 18. Retrieved from https:// www.ncbi.nlm.nih.gov/pmc/articles/PMC5964704/pdf/13011_2018_Article_158. pdf.

Jurgens, R. (2008). Nothing about us without us" - Greater, meaningful involvement of people who use illegal drugs: A public health, ethical, and human rights imperative (International edition). Toronto.

Keats, J., Micallef, M., Grebely, J., Hazelwood, S., Everingham, H., Shrestha, N., \& Dunlop, A. (2015). Assessment and delivery of treatment for hepatitis C virus infection in an opioid substitution treatment clinic with integrated peer-based support in Newcastle, Australia. International Journal of Drug Policy, 26(10), 999-1006. https://doi.org/10.1016/j.drugpo.2015.07.006.

Legal and Discrimination Working Party of MACBBVS (2013). A series of 7 papers on the impacts of discrimination and criminalisation on public health approaches to blood borne viruses and sexually transmissible infections. Prepared for the Commonwealth Ministerial Advisory Committee on BBV and STIs (MACBBVS). Retrieved from http:// www.hrc.act.gov.au/humanrights/content.php/category.view/id/215.

Luke, D. A., \& Stamatakis, K. A. (2012). Systems science methods in public health: Dynamics, networks, and agents. Annual Review of Public Health, 33, 357-376. Retrieved from http://www.ncbi.nlm.nih.gov/pmc/articles/PMC3644212/.

Mabry, P. L., \& Kaplan, R. M. (2013). Systems science: A good investment for the public's health. Health Education \& Behavior, 40(1 suppl), 9S-12S. https://doi.org/10.1177/ 1090198113503469.

MacLellan, J., Surey, J., Abubakar, I., Stagg, H. R., \& Mannell, J. (2017). Using peer advocates to improve access to services among hard-to-reach populations with hepatitis C: A qualitative study of client and provider relationships. MacLellan2017 Harm Reduction Journal, 14(1), 76. https://doi.org/10.1186/s12954-017-0202-x.

Madden, A., \& Wodak, A. (2014). Australia's response to HIV among people who inject drugs. AIDS Education and Prevention, 26(3), 234-244. Retrieved from http://www. scopus.com/inward/record.url? eid =2-s2.0-84903769567\&partnerID =40\&md5 = b9f0cc430006afdb16d807e49fd26932.

Marshall, Z., Dechman, M. K., Minichiello, A., Alcock, L., \& Harris, G. E. (2015). Peering into the literature: A systematic review of the roles of people who inject drugs in harm reduction initiatives. Drug and Alcohol Dependence, 151, 1-14. https://doi.org/ 10.1016/j.drugalcdep.2015.03.002.

Martin, N. K., Vickerman, P., Dore, G. J., Grebely, J., Miners, A., Cairns, J., \& Martin, T. C. (2016). Prioritization of HCV treatment in the direct-acting antiviral era: An economic evaluation. Journal of Hepatology, 65(1), 17-25.

McNeil, R., Small, W., Lampkin, H., Shannon, K., \& Kerr, T. (2014). "People knew they could come here to get help": An ethnographic study of assisted injection practices at a peer-run' unsanctioned' supervised drug consumption room in a Canadian setting. AIDS and Behavior, 18(3), 473-485. https://doi.org/10.1007/s10461-013-0540-y.

Meadows, D. H., \& Wright, D. (2008). Thinking in systems: A primer. White river junction. Vermont USA: Chelsea Green Publishing.

Midgley, G. (Ed.). (2003). Systems thinking. Thousand Oaks, CA: Sage Publications.

Needle, R. H., Burrows, D., Friedman, S. R., Dorabjee, J., Touzé, G., Badrieva, L., \& Latkin, C. (2005). Effectiveness of community-based outreach in preventing HIV/AIDS among injecting drug users. International Journal of Drug Policy, 16(Supplement 1), 45-57. https://doi.org/10.1016/j.drugpo.2005.02.009.

O'Gorman, A., Quigley, E., Zobel, F., \& Moore, K. (2014). Peer, professional, and public: An analysis of the drugs policy advocacy community in Europe. International Journal of Drug Policy, 25(5), 1001-1008. https://doi.org/10.1016/j.drugpo.2014.04.020.

Osborn, B., \& Small, W. (2006). "Speaking truth to power": The role of drug users in influencing municipal drug policy. International Journal of Drug Policy, 17(2), 70-72. https://doi.org/10.1016/j.drugpo.2005.09.001.

Ostrom, E. E., Dietz, T. E., Dolšak, N. E., Stern, P. C., Stonich, S. E., \& Weber, E. U. (2002). The drama of the commons. National Academy Press.

Pawson, R., \& Tilley, N. (1997). Realistic evaluation. London: Sage.

Peters, D. (2014). Advancing the application of systems thinking in health: Why use systems thinking? Health Research Policy and Systems, 12, 51. Retrieved from http:// www.ncbi.nlm.nih.gov/pmc/articles/PMC4245196/pdf/12961_2014_Article_342. pdf.

Pitcher, A. B., Borquez, A., Skaathun, B., \& Martin, N. K. (2019). Mathematical modeling of hepatitis $\mathrm{C}$ virus (HCV) prevention among people who inject drugs: A review of the 
literature and insights for elimination strategies (In press, online) Journal of Theoretical Biology. https://doi.org/10.1016/j.jtbi.2018.11.013.

Ratliff, E. A., Kaduri, P., Masao, F., Mbwambo, J. K. K., \& McCurdy, S. A. (2016). Harm reduction as a complex adaptive system: A dynamic framework for analyzing Tanzanian policies concerning heroin use. International Journal of Drug Policy, 30, 7-16. https://doi.org/10.1016/j.drugpo.2015.12.008.

Scott, N., McBryde, E. S., Thompson, A., Doyle, J. S., \& Hellard, M. E. (2017). Treatment scale-up to achieve global HCV incidence and mortality elimination targets: A costeffectiveness model. Gut, 66(8), 1507-1515.

Sendziuk, P. (2003). Learning to trust: Australian responses to AIDS. UNSW Press.

Ti, L., Hayashi, K., Hattirat, S., Suwannawong, P., Kaplan, K., \& Kerr, T. (2015). 'Drug users stick together': HIV testing in peer-based drop-in centres among people who inject drugs in Thailand. Sexual Health, 12(3), 263-268. https://doi.org/10.1071/ SH14107.

Tookey, P., Mason, K., Broad, J., Behm, M., Bondy, L., \& Powis, J. (2018). From client to co-worker: A case study of the transition to peer work within a multi-disciplinary hepatitis c treatment team in Toronto, Canada (Tookey2018) Harm Reduction Journal, 15(1), 41. https://doi.org/10.1186/s12954-018-0245-7.

Treloar, C., Rance, J., Bath, N., Everingham, H., Micallef, M., Day, C., \& Dore, G. J. (2015). Evaluation of two community-controlled peer support services for assessment and treatment of hepatitis $C$ virus infection in opioid substitution treatment clinics: The ETHOS study, Australia. International Journal of Drug Policy, 26, 992-998. https://doi.org/10.1016/j.drugpo.2015.01.005.

Ward, J. W. (2016). Global elimination of hepatitis C virus. Gastroenterology \& Hepatology, 12(10), 632.

Webel, A. R., Okonsky, J., Trompeta, J., \& Holzemer, W. L. (2010). A systematic review of the effectiveness of peer-based interventions on health-related behaviors in adults. American Journal of Public Health, 100(2), 247-253.

Williams, B., \& Hummelbrunner, R. (2010). Systems concepts in action: A practitioner's toolkit. Stanford University Press. 